\title{
Experimental Model of Human Corpus Cavernosum Smooth Muscle Relaxation
}

\author{
Rommel P. Regadas, Maria E. A. Moraes, Francisco J. C. Mesquita, Joao B. G. Cerqueira, Lucio \\ F. Gonzaga-Silva
}

Department of Surgery (RPR, JBGC, LFGS, FJCM) and Department of Pharmacology (MEAM), School of Medicine, Federal University of Ceara, Fortaleza, Ceara, Brazil

\begin{abstract}
Purpose: To describe a technique for en bloc harvesting of the corpus cavernosum, cavernous artery and urethra from transplant organ donors and contraction-relaxation experiments with corpus cavernosum smooth muscle.

Materials and Methods: The corpus cavernosum was dissected to the point of attachment with the crus penis. A $3 \mathrm{~cm}$ segment (corpus cavernosum and urethra) was isolated and placed in ice-cold sterile transportation buffer. Under magnification, the cavernous artery was dissected. Thus, $2 \mathrm{~cm}$ fragments of cavernous artery and corpus cavernosum were obtained. Strips measuring $3 \times 3 \times 8 \mathrm{~mm}^{3}$ were then mounted vertically in an isolated organ bath device. Contractions were measured isometrically with a Narco-Biosystems force displacement transducer (model F-60, Narco-Biosystems, Houston, TX, USA) and recorded on a 4-channel Narco-Biosystems desk model polygraph.

Results: Phenylephrine $(1 \mu \mathrm{M})$ was used to induce tonic contractions in the corpus cavernosum ( 3 - $5 \mathrm{~g}$ tension) and cavernous artery ( $0.5-1 \mathrm{~g}$ tension) until reaching a plateau. After precontraction, smooth muscle relaxants were used to produce relaxation-response curves $\left(10^{-12} \mathrm{M}\right.$ to $\left.10^{-4} \mathrm{M}\right)$. Sodium nitroprusside was used as a relaxation control.

Conclusion: The harvesting technique and the smooth muscle contraction-relaxation model described in this study were shown to be useful instruments in the search for new drugs for the treatment of human erectile dysfunction.
\end{abstract}

Key words: penis; cavernous artery; penile erection; experimental; erectile dysfunction

Int Braz, J Urol. 2010; 36: 490-6

\section{INTRODUCTION}

Erectile dysfunction (ED) affects approximately 150 million people worldwide. The prevalence of ED in Brazil is high: more than $40 \%$ of Brazilian men between 40 and 70 years of age suffer from ED and more than a million new cases are registered annually $(1,2)$.

Although phosphodiesterase type-5 (PDE-5) inhibitors have revolutionized the treatment of erectile dysfunction, many patients, mostly those with endo- thelial dysfunction ( $56 \%$ of cases), do not benefit from this form of therapy (3).

At present many studies are being carried out using nitric oxide (NO) donors, guanylyl cyclase activators (both soluble intracellular and membranebound isoforms), ion channel agonists and RhoA-kinase inhibitors in order to formulate new drugs with different mechanisms of action to treat this patient population $(4,5)$.

The vast majority of these studies employ rat and rabbit corpus cavernosum due to the difficulty in 
obtaining samples of human tissue (5-7). However, at our Urology Service, experimental studies on ED have been in progress since 2004 using human corpus cavernosum tissue from organ donors.

The purpose of the present study was to provide a detailed description of the technique used for en bloc harvesting of the corpus cavernosum, cavernous artery and urethra of transplant organ donors and the methods used in contraction-relaxation experiments with corpus cavernosum smooth muscle.

\section{MATERIALS AND METHODS}

All study protocols were previously approved by the Human Subjects Research Ethics Committee of the Federal University of Ceará and by the National Research Ethics Committee of the Brazilian Ministry of Health.

Following authorization from the family, human corpus cavernosum was obtained from cadaver donors $(<40$ years) during surgery for organ transplantation.

After removal of the heart, liver and kidneys and through the same incision (xiphoid pubic), the corpus cavernosum was located above the pubic symphysis by digital hypodermic approach. The corpus cavernosum was dissected to the point of attachment with the ischiopubic ramus (crus penis) (Figure-1).

A $3 \mathrm{~cm}$ segment including the corpus cavernosum and urethra was isolated en bloc (Figure-2). No additional external incision was made at the end of procedure. Subsequently, the tissues were placed in ice-cold sterile transportation buffer (Collins solution) and processed within 1 hour after collection.

The samples were processed under stereoscopic magnification. The entire cavernous artery in the center of the corpus cavernosum was dissected and isolated from the surrounding cavernous tissues (Figure-3). Then cavernous tissues were separated from connective tissues and the tunica albuginea. Thus, $2 \mathrm{~cm}$ fragments of each cavernous artery and corpus cavernosum were obtained.

The corpus cavernosum fragments were cut into strips measuring approximately $3 \times 3 \times 8 \mathrm{~mm}^{3}$ and mounted vertically under $1 \mathrm{~g}$ resting tension. The cavernous artery was cut into $5 \mathrm{~mm}$ rings and mounted

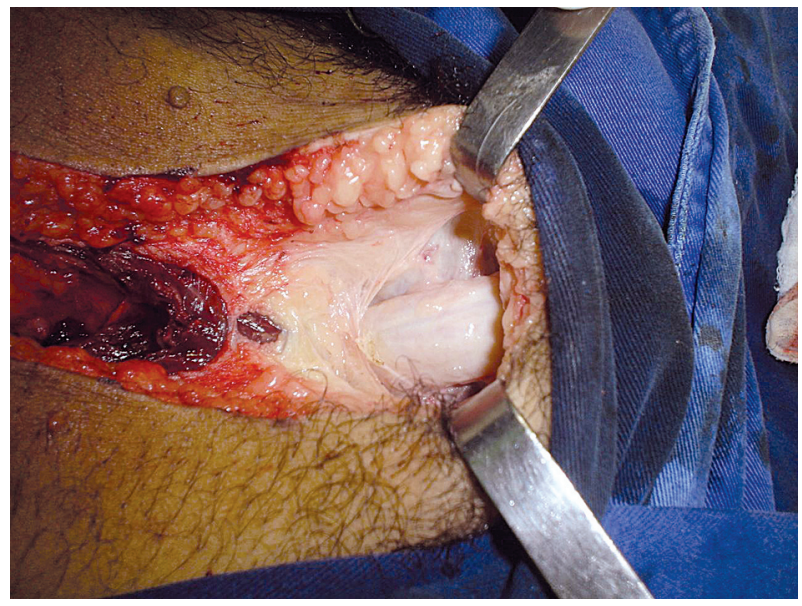

Figure 1-Dissection of the corpora cavernosa to the point of attachment with the crus penis.

horizontally under $0.2 \mathrm{~g}$ resting tension. The tissues were maintained in $5 \mathrm{~mL}$ organ chambers containing Krebs-Henseleit medium composed of 114.6 $\mathrm{mM} \mathrm{NaCl}, 4.96 \mathrm{mM} \mathrm{KCl}, 1.3 \mathrm{mM} \mathrm{MgSO}, 2.0 \mathrm{mM}$ $\mathrm{CaCl}_{2}, 1.23 \mathrm{mM} \mathrm{NaH}_{2} \mathrm{PO}_{4}, 25 \mathrm{mM} \mathrm{NaHCO}_{3}$ and 3.6 $\mathrm{mM}$ glucose, enriched with $10 \mu \mathrm{M}$ guanethidine and $10 \mu \mathrm{M}$ indomethacin $\left(\mathrm{pH} 7.4,37^{\circ} \mathrm{C}\right.$, gassed with $5 \%$ $\mathrm{CO}_{2}$ and $95 \% \mathrm{O}_{2}$ ).

The tissues were allowed to equilibrate for $90 \mathrm{~min}$ with washing at $15 \mathrm{~min}$ intervals. The ten-

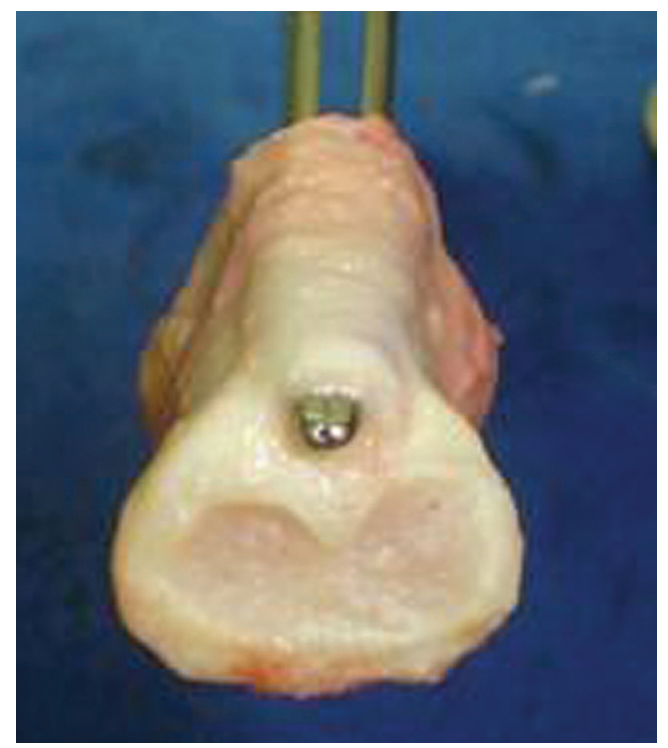

Figure 2-Corpora cavernosa and urethra. 


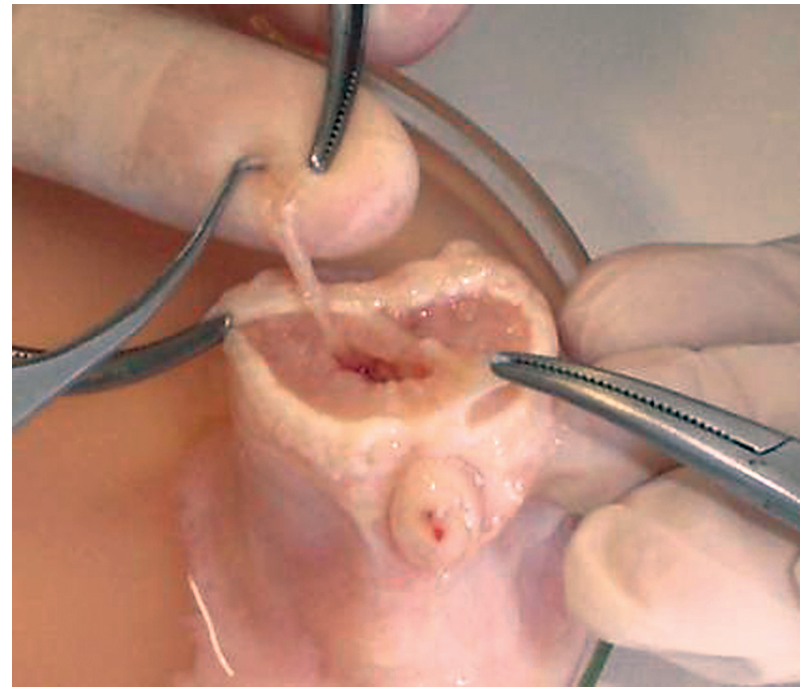

Figure 3 - Cavernous artery.

sion was measured by an isometric transducer (F-60 Narco-Biosystems connected to a 4-channel desk model polygraph) (Figure-4).

One micromole phenylephrine was added to the baths to obtain $60-70 \%$ submaximal smooth muscle contractions. Subsequently, concentrationresponse curves $\left(10^{-8} \mathrm{M}\right.$ to $\left.10^{-2} \mathrm{M}\right)$ to smooth-muscle relaxants or sodium nitroprusside (SNP), a nitric oxide donor, were plotted to check for endothelial functional integrity.

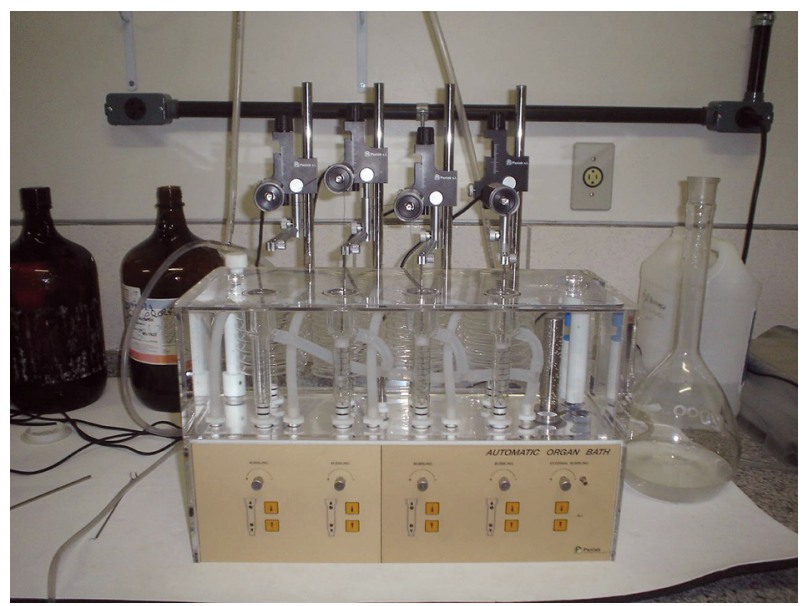

Figure 4-Isolated bathing system.

\section{RESULTS}

Phenylephrine $(1 \mu \mathrm{M})$ was used to induce tonic contractions in the corpus cavernosum $(3-5 \mathrm{~g}$ tension) and cavernous artery ( $0.5-1 \mathrm{~g}$ tension) until reaching a plateau. After precontraction, smooth muscle relaxants were used to produce relaxationresponse curves $\left(10^{-12} \mathrm{M}\right.$ to $\left.10^{-4} \mathrm{M}\right)$. SNP was used as a relaxation control.

A number of chemical substances have been used in our laboratory to induce smooth muscle relaxation, including $\mathrm{Ru}[(\mathrm{NH} 3) 4$ (caffeine)(NO)]C13, a nitric oxide donor. It completely relaxes the human corpus cavernosum and cavernous artery achieving an $\mathrm{E}_{\max }$ of $100 \%$ and an $\mathrm{EC}_{50}$ of $6.4 \pm 0.14$ (Figure-5).

Using preparations of corpus cavernosum with intact endothelium from human donors under 40 with no history of erectile dysfunction or cardiovascular risk factors (e.g. diabetes, hypertension and dyslipidemias), this physio-pharmacological model proved to be an attractive instrument in the search for new drugs for the treatment of human erectile dysfunction.

\section{COMMENTS}

PDE-5 inhibitors have revolutionized the treatment of erectile dysfunction. However, many patients with ED also suffer from endothelial dysfunction $(56 \%)$ and are therefore unresponsive to this class of drugs (3).

Endothelial dysfunction is often observed in patients with comorbidities such as arterial hypertension and diabetes mellitus. It is characterized by a deficiency in the endogenous production of $\mathrm{NO}$ (8).

In true ED, diabetes, hypertension, and dyslipidemia (components of the metabolic syndrome) tend to be associated with endothelial dysfunction. ED has also been reported to be a marker for cardiovascular arterial disease (9).

The search for new drugs capable of increasing the availability of endogenous NO has been a considerable challenge. Several experimental models have been used over the past decades based on rat, rabbit and human corpus cavernosum $(6,7,10,11)$. 


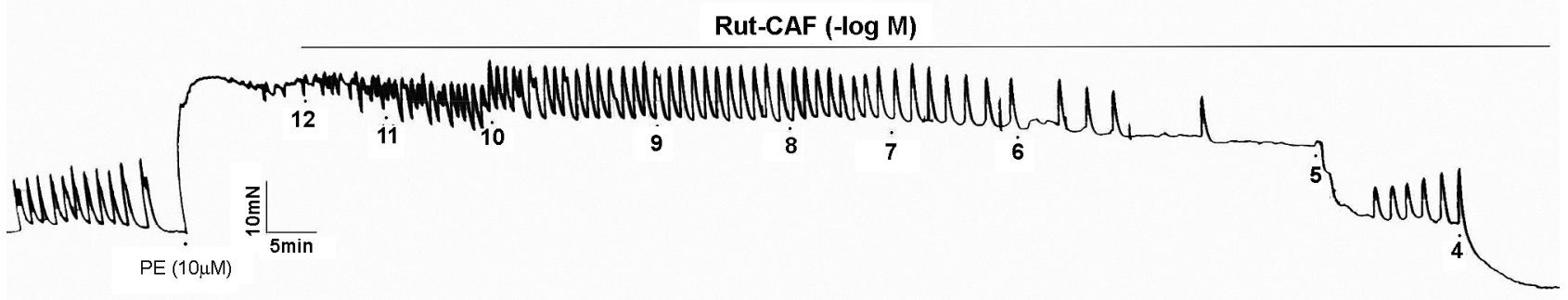

Figure 5 - Physiographic tracing of the Rut-CAF $\left(10^{-12}-10^{-4} \mathrm{M}\right)$ effect in human corpus cavernosum strips placed in

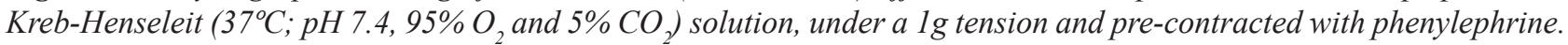
Vertical scale $=10 \mathrm{mN}$ and horizontal scale $=5 \mathrm{~min}$.

Using corpus cavernosum in vivo and other tissues (e.g. platelets) from species such as rats, rabbits and humans, Peng Wang et al. (12) concluded that, in spite of similar kinetics and enzymatic features, different PDEs have different sensitivities to inhibitors. This should be taken into account when working with experimental models of this type.

Our experimental model employed healthy corpus cavernosum tissues from young cadaver donors killed by trauma or stroke in order to minimize the concern about distortion of results caused by sample tissues of poor condition.

In contrast, in a study using a similar human corpus cavernosum model for the evaluation of the effect of sildenafil on enzymatic PDE inhibition and consequent smooth muscle relaxation, samples were obtained from patients with ED during surgery for penile prosthesis implantation, so it seems likely that in this case most of the subjects presented endothelial injury to some degree (6).

Another concern in this field of research is the availability of tissues to perform the experiments. In Ceará, eight organ transplantations are carried out every month, making it possible to complete studies without major interruptions.

Seidler et al. (4) worked on a similar model using corpus cavernosum donated by patients undergoing sex reassignment surgery as treatment for transsexualism and gender identity disorder. In spite of the good condition of the tissues, the small number of men submitting to this type of procedure limits the possibility of collecting sufficient tissue for experimental work.
The present paper presents a comprehensive model for harvesting human corpus cavernosum tissues and for carrying out smooth muscle relaxation experiments in vivo. Healthy human corpus cavernosum is removed from cadaver donors and subjected to experiments in isolated baths. The technique allows to dissect and isolate the corpus cavernosum, cavernous artery and urethra.

The importance of the technique lies in that it makes it possible to test a range of new drugs, including stable NO donors, guanylyl cyclase activators and RhoA-kinase inhibitors, on smooth muscle corpus cavernosum, penile arteries and urethra (7,12$15)$.

\section{CONCLUSION}

This experimental model involves the dissection, harvesting, isolation and conservation of the human corpus cavernosum, cavernous artery and urethra under ideal conditions along with the accompanying physio-pharmacological studies. The feasibility and reproducibility of the model makes it an attractive instrument in the search for new drugs for the treatment of human erectile dysfunction.

\section{CONFLICT OF INTEREST}

None declared. 


\section{REFERENCES}

1. Moreira ED Jr, Bestane WJ, Bartolo EB, Fittipaldi JA: Prevalence and determinants of erectile dysfunction in Santos, southeastern Brazil. Sao Paulo Med J. 2002; 120: 49-54.

2. Moreira ED Jr, Lisboa Lôbo CF, Villa M, Nicolosi A, Glasser DB: Prevalence and correlates of erectile dysfunction in Salvador, northeastern Brazil: a population-based study. Int J Impot Res. 2002; 14(Suppl 2): S3-9.

3. Feldman HA, Goldstein I, Hatzichristou DG, Krane RJ, McKinlay JB: Impotence and its medical and psychosocial correlates: results of the Massachusetts Male Aging Study. J Urol. 1994; 151: 54-61.

4. Seidler M, Uckert S, Waldkirch E, Stief CG, Oelke M, Tsikas D, et al.: In vitro effects of a novel class of nitric oxide (NO) donating compounds on isolated human erectile tissue. Eur Urol. 2002; 42: 523-8.

5. Lopes LFG, Wieraszko AY, El-Sherif, Clarke MJ: Dtrans-labilization of Nitric Oxide in Ru-II Complexes by C-bound Imidazoles. Inorg-Chim Acta 2001; 312: 15-22.

6. Ballard SA, Gingell CJ, Tang K, Turner LA, Price ME, Naylor AM: Effects of sildenafil on the relaxation of human corpus cavernosum tissue in vitro and on the activities of cyclic nucleotide phosphodiesterase isozymes. J Urol. 1998; 159: 2164-71.

7. Prieto D, Rivera L, Recio P, Rubio JL, Hernández M, García-Sacristán A: Role of nitric oxide in the relaxation elicited by sildenafil in penile resistance arteries. J Urol. 2006; 175: 1164-70.

8. Rendell MS, Rajfer J, Wicker PA, Smith MD: Sildenafil for treatment of erectile dysfunction in men with diabetes: a randomized controlled trial. Sildenafil Diabetes Study Group. JAMA. 1999; 281: 421-6.

9. Palumbo PJ: Metabolic risk factors, endothelial dysfunction, and erectile dysfunction in men with diabetes. Am J Med Sci. 2007; 334: 466-80.

10. Thompson CS, Mumtaz FH, Khan MA, Wallis RM, Mikhailidis DP, Morgan RJ, et al.: The effect of sildenafil on corpus cavernosal smooth muscle relaxation and cyclic GMP formation in the diabetic rabbit. Eur J Pharmacol. 2001; 425: 57-64.

11. Angulo J, Cuevas P, Moncada I, Martín-Morales A, Allona A, Fernández A, et al:: Rationale for the combination of PGE(1) and S-nitroso-glutathione to induce relaxation of human penile smooth muscle. $\mathrm{J}$ Pharmacol Exp Ther. 2000; 295: 586-93.

12. Wang P, Wu P, Myers JG, Stamford A, Egan RW, Billah MM: Characterization of human, dog and rabbit corpus cavernosum type 5 phosphodiesterases. Life Sci. 2001; 68: 1977-87.

13. Martinez AC, García-Sacristán A, Rivera L, Benedito $\mathrm{S}$ : Biphasic response to histamine in rabbit penile dorsal artery. J Cardiovasc Pharmacol. 2000; 36: 737 43.

14. Matsumoto A, Morita T, Kondo S: Alpha-adrenoceptor-mediated penile erection in dogs: in vivo and in vitro observations. J Smooth Muscle Res. 2000; 36: 169-79.

15. Andersson KE, Gratzke C: Pharmacology of alpha1adrenoceptor antagonists in the lower urinary tract and central nervous system. Nat Clin Pract Urol. 2007; 4: 368-78.

\section{Correspondence address:}

Dr. Rommel Prata Regadas

Dr. Ratisbona, 208, Fatima

Fortaleza, Ceará, 60411-220, Brazil

Fax: + 5585 3366-8064

E-mail: rommelregadas@ig.com.br 


\section{EDITORIAL COMMENT}

Penile erection is a complex neurovascular event that relies on vasodilatation of erectile tissues due to neuronal and endothelial derived nitric oxide (NO) released by activation of parasympathetic nerves on sexual stimulation of the cavernous endothelial lining (1).

This sexual stimulus brings about blood flow into the corpus cavernosum and the consequent penile rigidity is maintained by means of a veno-occlusive mechanism.

This is enabled by the particular micro-architecture of the corpus cavernosum, which consents a sophisticated hemodynamic system.

Otherwise, the tunica albuginea plays a key role in the erectile function.

Being rich in elastic fibers it is able to resist overstretching of the corpus at raised levels of intracavernous pressure, compressing the trans-albugineal effluent veins, as well providing on inextensible protective structure to the arteriole and to the intracavernous nerves.

This function is possible due to its structure made of collagenic fibers linked by elastic fiber bridges (2,3).

Therefore, it is very important to keep its integrity to maintain its fundamental role in the erectile mechanism.

The presence of structural disorders like an excessive collagen deposition gives rise to the formation of a plaque, fibrotic first and then calcified, as can be found in Peyronie's disease.

Moreover, there is a significant decrease of elastic fiber concentration as well in these patients affected by induration penis plastica (4).

Similar changing were found in patients who underwent radical prostatectomy, where the trabecular elastic fibers and smooth muscle fibers were decreased and collagen content was significantly increased (5).

As age advances the gonadal steroid hormones, and in particular, testosterone production decreases (6), nerve conduction slows down and the efficiency of the vascular microcirculation of the penis is reduced.
Androgens are essential for the development, growth and maturation of erectile tissues, acting on the hemostatis in the corpora cavernosum, regulating the growth of smooth muscle and protein synthesis of the connective tissues.

Therefore, a decrease in their production could give rise to the switch from elastic fibers to collagen fibers, which is the basis of cavernosal fibrosis $(7,8)$.

Recent studies have shown that testosterone also regulates the expression of phosphodiesterasis type 5 (PDE5) (9).

It is known that erectile dysfunction (ED) affects 150 million people worldwide.

Until few years ago, it was thought that $90 \%$ of ED had a psychogenetic etiology.

Moreover, further neurophysiological, hemodynamical and pharmacological studies have helped us to understand better the complex biochemical and micro-anatomical mechanism of the erectile function, showing us that $50 \%$ of ED has an organic etiology (10).

On the other hand, even psychogenetic ED could be the consequence of an increase of adrenergic stimulation and having itself an organic origin (11).

The past 20 years have witnessed remarkable changes in the treatment of ED.

The emergence and the success of PDE5 inhibitors as effective therapy for erectile dysfunction is remarkable considering the intent behind the development of the original compound: initially designed as an antianginal agent, it quickly became apparent that the first PDE5 inhibitor on the market, sildenafil, displayed erectogenesis as a side effect, and the drug was soon recognized as a potential revolutionary treatment for ED..

Furthermore, sildenafil has been shown to prevent the progression of fibrosis of the corpus cavernosum in prostatectomized patients. Its efficacy seems to result from an anti-proliferative effect exerted on fibroblasts (12).

It is known that PDE-5 inhibitors have revolutionized the treatment of erectile dysfunction and changed the life of million people worldwide. 
However there still a high percentage of patients with ED that are also affected by endothelial dysfunction (56\%) and subsequently they are unresponsive to this class of drugs (13).

Although already extensively studied, NO donors continue to be an important topic as regards ED.

Many studies have been carried out to find new NO donors or new guanylyl cyclase activators to try to find new drugs to treat these patients who are non-responders to PDE-5 inhibitors (14).

The present work shows us a model for harvesting human corpus cavernosum tissues and for making smooth muscle relaxation experiments in vivo.

The healthy corpus cavernosum taken from young cadaver donors killed by trauma or stroke offer tissues in good condition.

In the literature, we have not found a similar approach due the difficulty to obtain samples of human tissues.

With this technique is possible to test new drugs, like NO donors, guanylyl cyclase activators and RohA-Kinase inhibitors on human smooth muscle tissues in vivo rather then using corpus cavernosum in vivo from animals like rats, or rabbits as it has been performed by Pen Wang et al. (15).

Finally, this harvesting technique and smooth muscle contraction-relaxation model could be a very useful instrument to help us to find new drugs to treat ED.

\section{REFERENCES}

1. Andersson KE, Wagner G: Physiology of penile erection. Physiol Rev. 1995; 75: 191-236.

2. Iacono F, Barra S, de Rosa G, Boscaino A, Lotti T: Microstructural disorders of tunica albuginea in patients affected by impotence. Eur Urol. 1994; 26: 233-9.

3. Iacono F, Barra S, Lotti T: Elastic fibre concentration in the tunica albuginea of corpora cavernosa and nocturnal tumescence monitoring. Int J Impot Res. 1995; 7: 63-70

4. Iacono F, Barra S, De Rosa G, Boscaino A, Lotti T: Microstructural disorders of tunica albuginea in patients affected by Peyronie's disease with or without erection dysfunction. J Urol. 1993; 150: 1806-9.
5. Iacono F, Giannella R, Somma P, Manno G, Fusco F, Mirone V: Histological alterations in cavernous tissue after radical prostatectomy. J Urol. 2005; 173: 16736.

6. Traish A, Kim N: The physiological role of androgens in penile erection: regulation of corpus cavernosum structure and function. J Sex Med. 2005; 2: 759-70.

7. Traish AM, Guay AT: Are androgens critical for penile erections in humans? Examining the clinical and preclinical evidence. J Sex Med. 2006; 3: 382-404; discussion 404-7.

8. Park K, Seo JJ, Kang HK, Ryu SB, Kim HJ, Jeong GW: A new potential of blood oxygenation level dependent (BOLD) functional MRI for evaluating cerebral centers of penile erection. Int J Impot Res. 2001; 13: 73-81.

9. Morelli A, Filippi S, Mancina R, Luconi M, Vignozzi L, Marini M, et al.: Androgens regulate phosphodiesterase type 5 expression and functional activity in corpora cavernosa. Endocrinology. 2004; 145: 225363. Erratum in: Endocrinology. 2004; 145: 3152.

10. Kaiser FE: Erectile dysfunction in the aging man. Med Clin North Am. 1999; 83: 1267-78.

11. Iacono F, Barra S, Lotti T: Evaluation of penile deep arteries in psychogenic impotence by means of duplex ultrasonography. J Urol. 1993; 149: 1262-4.

12. Iacono F, Prezioso D, Somma P, Chierchia S, Galasso R, Micheli P: Histopathologically proven prevention of post-prostatectomy cavernosal fibrosis with sildenafil. Urol Int. 2008; 80: 249-52.

13. Feldman HA, Goldstein I, Hatzichristou DG, Krane RJ, McKinlay JB: Impotence and its medical and psychosocial correlates: results of the Massachusetts Male Aging Study. J Urol. 1994; 151: 54-61.

14. Seidler M, Uckert S, Waldkirch E, Stief CG, Oelke $\mathrm{M}$, Tsikas $\mathrm{D}$, et al.: In vitro effects of a novel class of nitric oxide (NO) donating compounds on isolated human erectile tissue. Eur Urol. 2002; 42: 523-8.

15. Wang P, Wu P, Myers JG, Stamford A, Egan RW, Billah MM: Characterization of human, dog and rabbit corpus cavernosum type 5 phosphodiesterases. Life Sci. 2001; 68: 1977-87.

Dr. Fabrizio Iacono

Dr. Domenico Taglialatela \& Dr. Antonio Ruffo Department Urology University "Federico II" Naples, Italy E-mail:fiacon@tin.it 